\title{
Léxico y ortodoxia religiosa en el Panarion de Epifanio de Salamis
}

\author{
Alberto J. Quiroga Puertas \\ Universidad de Granada \\ aquiroga@ugr.es
}

Hasta bien entrado el siglo XX, el estudio de textos de contenido cristiano mediante el empleo de una metodología afín a la crítica literaria clásica había sido una rara avis en el ámbito académico de los estudios patrísticos. Gracias al giro impulsado por la disciplina de la Antigüedad Tardía ahora podemos analizar y estudiar los textos del cristianismo de época imperial con rigor filológico y aplicando criterios propios de la retórica y de la poética clásicas ${ }^{1}$. Nos hallamos, afortunadamente, en un periodo en el que la synthèse entre l'Écriture et l'esthétique sophistique ${ }^{2}$ marca la pauta de los estudios literarios e historiográficos que sobre los textos cristianos de los primeros siglos de nuestra era se vienen realizando. Así pues, además de haber sido ampliamente empleadas en comentarios y obras de carácter exegético ${ }^{3}$, la retórica, la poética y la estilística se han convertido en útiles disciplinas que ayudan a profundizar en las implicaciones religiosas, políticas y teológicas de los textos cristianos de contenido apologético o polémico.

Dentro de este marco metodológico, mi breve contribución a este volumen ${ }^{4}$ versará sobre el empleo de los vocablos derivados de los compuestos $\lambda \varepsilon \xi 1 \theta \eta \rho-$ y $\lambda \varepsilon \pi \tau o \lambda$ o en el Panarion de Epifanio de Salamis, ya que ambos representan dos polos opuestos de la exégesis literaria practicada por Epifanio, y cuyo empleo fue puesto al servicio de la defensa de la ortodoxia religiosa y de la descalificación de la exégesis he-

\footnotetext{
${ }^{1}$ Una magnífica puesta al día del tema se halla en L. Pernot, «Christianisme et Sophistique», Papers on Rhetoric 4 (2002), pp. 245-262. Igualmente, vid. Av. Cameron, «The long Late Antiquity: a late twentiethcentury model», T.P. Wiseman (ed.),Classics in Progress: Essays on Ancient Greece and Rome, Oxford, 2002, p. 180s.: Now, in contrast, Christianity and Christian writing in the Roman Empire have benefited from a quite different and non-confessional approach, and this in itself made available a literary vast amount of material hitherto largely passed over (...) One no longer has to be a Christian to give Christianity an important place in the history of late antiquity.

2 J. Schamp, «Sophistes à l'ambon. Esquisses pour la Troisième Sophistique comme paysage littéraire», E. Amato, A. Roduit y M. Steirück (eds.), Approches de la Troisième Sophistiques. Hommages à Jacques Schamp, Bruxelles, 2006, p. 289.

${ }^{3}$ Para este particular, vid. A. Viciano, «Las Scriptorum Interpretationes en la Antigüedad Tardía», Minerva 5 (1991), pp. 105-109.

${ }^{4}$ Deseo hacer constar mi sincero agradecimiento a la profesora Juana Torres por su amable invitación a participar en este libro.
} 
rética. De este modo, en primer lugar, aportaré una breve reseña de la concepción de la ortodoxia religiosa de Epifanio; a continuación, analizaré los ejemplos en los que los vocablos compuestos $\lambda \varepsilon \xi_{1} \theta \eta \rho-$ y $\lambda \varepsilon \pi \tau$ - $\lambda$ o $\gamma$ - son empleados en el Panarion con una clara vocación polémica. Finalmente, contextualizaré su empleo en el marco de las disputas doctrinales de finales del siglo IV.

Pocos autores cristianos de la Antigüedad tardía presentan un pensamiento teológico tan uniforme y dogmático como el de Epifanio. Su defensa de la ortodoxia religiosa y del cristianismo homoousios es coherente a lo largo de su obra y constituye su principal leitmotiv. El dogmatismo de Epifanio rechazaba cualquier creencia basada en fundamentos alejados del nicenismo ortodoxo o relacionada con doctrinas origenistas, ya que, según Epifanio, Orígenes era la raíz y causa de gran parte de las herejías que azotaban el cristianismo del siglo IV (64.4.1-3) . Desde su nombramiento como obispo de Salamis, en Chipre, mantuvo una intensa actividad religiosa (tanto apologética como polémica) y ejerció una importante influencia en su entorno más cercano así como en el Oriente cristiano, interviniendo activamente en los intentos por pacificar el cisma meleciano de la sede antioquena ${ }^{6}$. De su correspondencia con Basilio de Cesarea conservamos una carta en la que éste contesta a las preocupaciones eclesiásticas y teológicas que constituyeron una constante durante el obispado de Epifanio ${ }^{7}$. Es significativo del énfasis y de la preocupación por la ortodoxia del obispo de Salamis el hecho de que Basilio se refiera en su contestación al catálogo de desdichas que asolan la Iglesia (Ep.

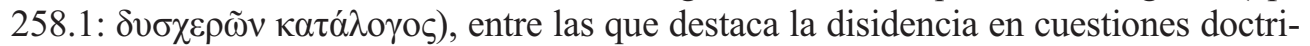

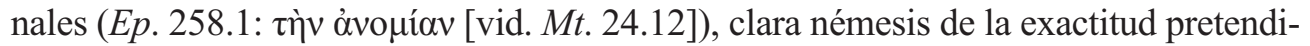

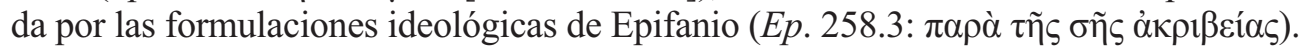

Fruto de tal preocupación por mantener la ortodoxia nicena es el Panarion, obra escrita a finales de la década del $370^{8}$, un periodo en el que el surgimiento de continuos cismas internos hacía necesaria la creación de obras como este botiquín (o «re-

\footnotetext{
${ }^{5}$ Sobre su vida y obra, J.F. Dechow, Dogma and mysticism in early Christianity: Epiphanius of Cyprus and the Legacy of Origen, Leuven, 1988, pp. 12-17; P. Nautin, «Épiphane (Saint) de Salamine», A. Baudrillart et alii (eds.), Dictionnaire D'Histoire et de Geographie Ecclesiastiques, Paris, 1963, vol. 15, pp. 617-631; A. Pourkier, L'hérésiologie chez Epiphane de Salamine, Paris, 1992, pp. 29-47; W. Schneemelcher, «Epiphanius von Salamis», F.J. Klauser et alii (eds.), Reallexikonfür Antike und Christentum, Stutgartt, 1962, pp. 909-927. Para su anti-origenismo, C. Riggi, «La figura di Epifanio nel IV secolo», SP 8.2, (1966), pp. 92-97. Un panorama general de la cuestión, en E.A. Clark, The Origenist Controversy. The Cultural Construction of an early Christian debate, Princeton, 1992.

${ }^{6}$ Sobre su impacto en la sociedad oriental de su tiempo, Sócrates $H E$ 5.32; 6.10; 7.27; Sozomeno HE 6.10. También C. Riggi, op. cit., 1966, pp. 86-107, esp. 86s. Para la recepción de su figura entre los siglos V-X, vid. C. Rapp, The Vita of Epiphanius of Salamis. An Historical and Literary Study, Tesis Doctoral, Oxford, 1992, pp. 32-43. Sobre su papel en el cisma meleciano, vid. J.F. Dechow, op. cit., pp. 57-123; G. Fernández, «La autocefalia de la Iglesia chipriota, una consecuencia del cisma del siglo IV en la cristiandad de Antioquía», Espacio, Tiempo y Forma. Serie 2, $H^{a}$. Antigua 8 (1995), pp. 501-505; Y.R. Kim, «Reading the Panarion as Collective Biography: the Heresiarch as Unholy Man», VCh 64 (2010), pp. 384-386; F.D. Williams, The Panarion of Epiphanius of Salamis, Leiden, 1987, vol. I, pp. XII-XIV. Vid. también la Ep. 258.3 de Basilio de Cesarea.

${ }^{7}$ M. Girardi, «Pluralità, convivenze e conflitti religiosi nell'ep. 258 di Basilio di Cesarea ad Epifanio di Salamina», Classica et Christiana 3 (2007), pp. 151-168.

${ }^{8}$ J.F. Dechow, op. cit., p. 13; M. Marcos, «Definiendo al hereje en el cristianismo antiguo. Los tratados De haeresibus», G. Bravo y R. González Salinero (eds.), Minorías y sectas en el mundo Romano, Madrid, 2006,
} 
medio contra todas las herejías», según otras traducciones del título original $)^{9}$. Tanto la naturaleza altamente tendenciosa del tipo de literatura adversus haereses al que pertenece el Panarion, como el carácter dogmático de Epifanio contribuyen a que esta obra haya sido considerada una «compilación compuesta de verdades, medias verdades, rumores e invectivas ${ }^{10}$. Con todo, a pesar de que la heresiología no acaba de ser considerada como un género literario con entidad propia ${ }^{11}$, creo que es pertinente y útil leer textos heresiológicos como el Panarion con los fundamentos propios de las disciplinas de la literatura y de la retórica. En un reciente trabajo, Kim propone leer esta obra de Epifanio en clave retórica por su naturaleza eminentemente persuasiva y generadora de corrientes de opinión ${ }^{12}$. Desde un punto de vista literario, opiniones como las de Chadwick, según el cual Epifanio profesó a rigorous hostility to every sort of intelectual pretension, including theological speculation ${ }^{13}$, dependen en exceso de la comparación de sus escritos con la plétora de obras de muchos de sus coetáneos (principalmente los eruditos padres Capadocios ${ }^{14}$ ), y están siendo revisadas a la luz de nuevos trabajos monográficos. Así, el traductor al inglés de Epifanio, F. Williams, estima que el vocabulario del obispo es by no means uncultivated [...] Epiphanius 'vocabulary is large, and his idiom varied and flexible ${ }^{15}$, animando a considerar la declaración de Epifanio de escribir en un estilo llano (Proemio II.2.6: $\dot{\alpha} \pi \lambda \tilde{\eta}$

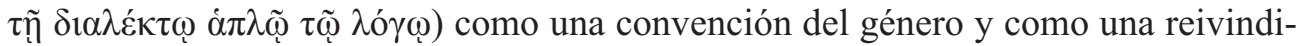
cación ideológica. Así, C. Riggi estima que la alusión al estilo llano non si trata soltanto di un retorico genus dicendi simplex ma anche di una concreta realizzazione della divina immagine nell' uomo ${ }^{16}$. Como intentaré demostrar a continuación mediante el estudio de dos vocablos usados por Epifanio, el obispo de Salamis manejó con pericia la adecuación del vocabulario a la redacción de su obra heresiológica, considerando que cualquier desviación del prurito filológico debido a la hora de leer las Escrituras acababa por desembocar en la formación de herejías.

pp. 159-168, p.160-161. Para una datación más tardía, vid. M. Rodríguez Gervás, «Infundios y verdades. Epifanio de Salamina y el Evangelio de Judas», ARYS 7 (2006-2008), p. 145.

${ }^{9} \mathrm{~J}$. McClure, «Hadbooks against heresy in the West, from the Late Fourth Century to the Late Sixth centuries», JThS 30 (1979), pp. 186-197.

${ }^{10}$ M. Rodríguez Gervás, op. cit., p. 157; M. Marcos, op. cit., p. 161. De hecho, C. Riggi, 1966, op. cit., p. 88 abre una sección de su trabajo con el epígrafe «Le due grandi accuse: ingegno extremamente limitato e zelo esasperatamente fanatico».

${ }^{11}$ Sobre la pertinencia de estudiar las heresiologías como textos literarios, vid. Av. Cameron, «How to Read Heresiology», JMEMS 33.3 (2003), pp. 471-492, esp. p. 471. Nótese el matiz despectivo de J. Verheyden, «Epiphanius of Salamis on Beasts and Heretics. Some introductory comments», Journal of Eastern Christian Studies 60 (2003), p. 183: one could say that, according to the expectations of the genre, as an heresiologist he was made of the right stuff.

${ }^{12}$ Y.R. Kim, op. cit., p. $385 \mathrm{~s}$.

${ }^{13}$ H. Chadwick, The Early Church, London, 1967, p. 184. También J. Verheyden, op. cit., p.183s.

${ }^{14}$ Ibidem, p. $182 \mathrm{~s}$.

${ }^{15}$ F.D. Williams, op. cit., p. XXI. Una opinión radicalmente contraria en C. Riggi, 1966, op. cit., p. 88.

${ }^{16}$ Sobre las intenciones de Epifanio en su prólogo de escribir, vid. C. Riggi, «Epifanio e il biblico dialogo coi non cristiani nella cornice del Panarion», Salesianum XXXV.1 (1974), pp. 231-259, especialmente p. 235. Para un muy completo y erudito estudio de la lengua de Epifanio, vid. J. Dummer, Philologia Sacra et Profana. Ausgewählte Beiträge zur Antike und zu ihrer Wirkungsgeschichte, Sttutgart, 2006, pp. 29-72. 


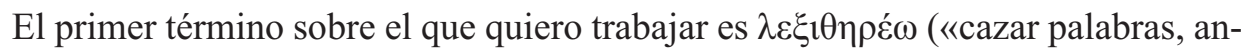
dar a la búsqueda de vocablos»), un verbo cuya primera aparición se da en las Noches Áticas de Aulo Gelio, quien se valió de este hápax para criticar el excesivo celo filológico de Plutarco al criticar algunos escritos de Epicuro (NA 2.9: Nimis minute ac prope etiam subfrigide Plutarchus in Epicuro accusando $\lambda \varepsilon \xi(\theta \eta \rho \varepsilon \tilde{i})^{17}$. El hecho de que $\lambda \varepsilon \xi 1 \theta \eta \rho \varepsilon ́ \omega$ se acuñara en relación al excesivo prurito filológico y apego al texto contribuyó para que se usara en el ámbito del cristianismo, religión en la que la exégesis textual fue causa de continuas controversias. Así, autores como Clemente de Alejandría, Orígenes o el diálogo De Recta in Deum Fide introdujeron el uso de

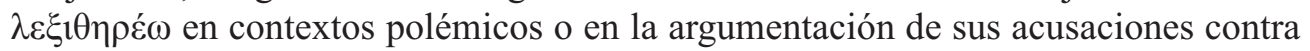
aquellos que buscaban una lectura heterodoxa en las Escrituras ${ }^{18}$.

Siendo éste el contexto en el que se empleó $\lambda \varepsilon \xi \xi \theta \eta \rho \varepsilon ́ \omega$, no es de extrañar que Epifanio recurriera a este término para criticar las lecturas heréticas de las sectas que condena en su Panarion, ya que la «caza de palabras» que implica el verbo $\lambda \varepsilon \xi 1 \theta \eta \rho \varepsilon ́ \omega$ acababa por constituir una desviación de la ortodoxia doctrinal nicena que él defendía. Así, en 30.25.1-4 critica a los ebionitas por sus erróneas interpretaciones de varios pasajes bíblicos (Phil. 3:5; Gal. 1:14, 2:9; 2 Cor. 11:22; Hechos 22:3) en los que su búsqueda de lecturas heterodoxas (lo que les vale el calificativo de $\tau$ oĩ $\lambda \varepsilon \xi \xi ı \eta \rho о v \tilde{l}$, 30.25.1) les lleva a dudar del origen e intenciones de la predicación de Pablo y Pe$\mathrm{dro}^{19}$. Igualmente, Epifanio critica a la secta gnóstica de los Severianos por emprender una búsqueda de palabras y lecturas heterodoxas tanto en los libros canónicos como en los apócrifos; similar imputación recae sobre aquellos que no reconocen los escritos de Juan y sobre los apolinaristas, estos últimos por sus continuas batallas dialécticas sobre sus interpretaciones de paradojas bíblicas ${ }^{20}$. En estos ejemplos, Epifanio de Salamis continúa los ataques doctrinales emprendidos por Ireneo de Lyon y por Eusebio de Cesarea ${ }^{21}$. Con todo, son los arrianos los que son acusados con mayor fre-

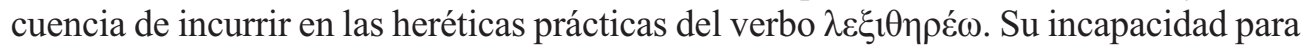
comprender cuándo realizar una lectura metafórica o literal de las Escrituras y sus errores doctrinales referentes a la concepción de la Trinidad viene motivada, según Epifanio, por su afán de encontrar interpretaciones heterodoxas alejadas del nicenismo ortodoxo, incurriendo de este modo en $\lambda \varepsilon \xi 1 \theta \eta \rho i ́ \alpha ~(69.50 .1 ; 69.61 .1 ; 69.76 .4)$.

${ }^{17}$ R. Marache y Y. Julien, Aulus Gellius. Les nuits attiques, Paris, 1967-1968, p. 97 n. 1: $\lambda \varepsilon \xi 1 \theta \eta \rho \varepsilon \tilde{i}$ est hapax: il signifie faire la chasse aux mots. Il ne s'agit pas ici de la chasse aux mots telle que la pratiquait Fronton, mais de la recherche trop subtile de nuances de sens.

${ }^{18}$ Clem. Paed. 1.6.45.3; Or. De Orig., 3.1.16; Adam. 90.12, 236.12. Ya en el siglo V, Soc. HE 6.22.

19 Sobre los textos en los que se basaron los ebionitas, vid. J.R. Edwards, «The Gospel of the Ebionites and the Gospel of Luke», NTS 48.4 (2002), pp. 568-586. Vid. también J. Verheyden, op. cit., pp. 202-205.

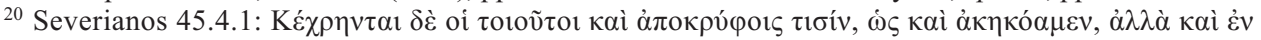

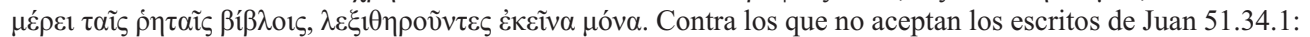

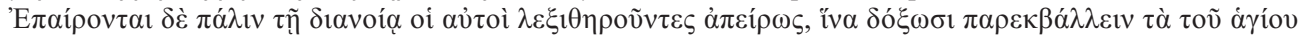

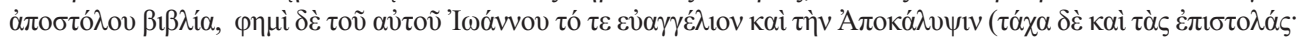

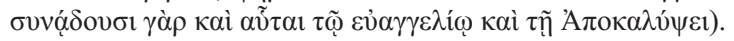

${ }_{21}$ Vid. Eusebio de Cesarea HE 4.29.4-5; 7.25-2-3; Ireneo de Lyon, Adv. Herej., 3.11.9. Apolinaristas 77.33.3:

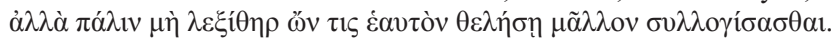


Este retrato de herejes como cazadores de palabras funciona a dos niveles en el Panarion de Epifanio. Por un lado, en el ámbito religioso-doctrinal el uso de $\lambda \varepsilon \xi 1 \theta \eta \rho \varepsilon ́ \omega$ ayuda a enfatizar el retrato del hereje como aquel que se desvía de la doctrina establecida por la ortodoxia imperante. Como ha manifestado Le Boulluec en una monografía sobre el perfil que la literatura ortodoxa dibuja de los herejes: les hérétiques sont accusés de s'intéresser exclusivament aux mots, nombreaux et variables, fruits de l'invention humaine, qui s'opposent à l'unité et à la stabilité de la veritée ${ }^{22}$. En este sentido, el empleo de $\lambda \varepsilon \xi 1 \theta \eta \rho \varepsilon ́ \omega$ en Epifanio refuerza una de las líneas argumentales más frecuentes en la literatura heresiológica, la invención de palabras o términos

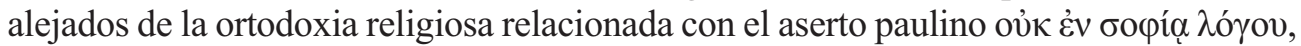

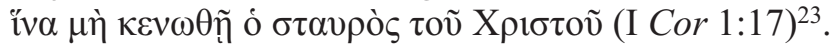

Por otro lado, en un nivel narrativo, el uso de un verbo compuesto como $\lambda \varepsilon \xi 1 \theta \eta \rho \varepsilon ́ \omega$ enfatiza la naturaleza irracional y bestial de las herejías descritas ${ }^{24}$. La parte verbal del compuesto proviene de la familia $\theta \eta \rho_{-}{ }^{25}$, que alude al mundo animal salvaje y que está en consonancia con un aspecto muy importante del Panarion. Desde el capítulo 21 hasta el 80, Epifanio compara cada herejía con un animal con el objeto de deshumanizar a los fundadores y seguidores de las herejías. Un reciente trabajo de Verheyden ha estudiado minuciosamente estas comparaciones, insistiendo en la originalidad y habilidad de Epifanio para insertar tales comparaciones en el largo catálogo de herejías ${ }^{26}$. Así, por ejemplo, las sectas acusadas de practicar la «caza de palabras» son comparadas con diversas fieras y animales mitológicos: los ebionitas con una hidra de muchas cabezas (30.1.1), los severianos con un escorpión (45.4.10), los que no aceptan los escritos de Juan son asemejados a ciempiés y a serpientes $(51.1 .1,35.4)$, y los arrianos son comparados también con serpientes e hidras (69.81.1). La comparación con tales animales salvajes, capaces de emponzoñar el cuerpo de la Iglesia ${ }^{27}$, animaliza a los herejes, incapaces de articular razonamientos lógicos. Por ello se lanzan a la caza

\footnotetext{
${ }^{22}$ La notion d'hérésie dans la littérature grecque IIe-IIIe siècles, vol. I, p.136. En el mismo sentido, Mar Marcos, «Definiendo al hereje en el cristianismo antiguo. Los tratados De haeresibus», G. Bravo y R. González Salinero (eds.), Minorías y sectas en el mundo Romano, Madrid, 2006, pp. 159-168, p. 165 ha subrayado que «escritura y tradición son el patrimonio de los que poseen la verdad, de la ortodoxia. Y no hay espacio para interpretaciones [...] Los cristianos no tienen necesidad de curiosidad (curiositas) después de Cristo. Curiositas y novitas son dos características de la perversitas herética. Los herejes, dice Ireneo, no tienen ni siguen la Tradición, carecen de una línea de sucesión apostólica: todas las herejías son de reciente formación y eso ya de por sí las descalifica. Vemos aquí la importancia del criterio de tradición como un sello de autenticidad».

${ }^{23}$ Sobre las distintas interpretaciones de este pasaje, vid. D. Litfin, St. Paul's Theology, Cambridge, 1994, pp. 4-18.

${ }^{24}$ Un panorama sobre la cuestión de las estrategias retóricas empleadas en el marco de los escritos polémicos, en J. Torres, «Retórica y argumentación en la literatura polémica cristiana de los siglos II-V», Mainake XXX (2008), pp. 271-280; Eadem, Ars persuadendi: Estrategias retóricas en la polémica entre paganos y cristianos al final de la Antigüedad, PubliCan, Santander, 2013.

${ }^{25}$ Sobre la etimología y derivados de $\theta \eta \rho-$, R. Beekes, Etymological Dictionary of Greek, Leiden, 2010, p. 547.

${ }^{26} \mathrm{~J}$. Verheyden, op. cit., pp. 150-154 para una lista de las herejías y los animales con los que son comparadas.

${ }^{27}$ I.S. Gilhus, Animals, gods, and humans: changing attitudes to animals in Greek, Roman, and early Christian ideas, London, 2006, p. 266.
} 
de significados y palabras ocultas como las bestias irracionales ( $\theta \tilde{\eta} \rho \varepsilon \varsigma)$ que eran para el ultra-ortodoxo obispo de Salamis ${ }^{28}$.

Frente a los herejes $\lambda \varepsilon \xi \hat{i} \theta \eta \rho \varepsilon \varsigma$, Epifanio opone la escrupulosidad y respeto al texto requerido a las Escrituras en la correcta profesión de fe mediante el empleo de palabras relacionadas con la raíz $\lambda \varepsilon \pi \tau o \lambda \circ \gamma-\left(« p r u r i t o\right.$, diligencia, minuciosidad») ${ }^{29}$. Él mismo se pone como ejemplo de $\lambda \varepsilon \pi \tau o \lambda$ ớí $\alpha$ en el tratamiento teórico que da a las herejías que condena: presume de narrar en detalle la herejía judía de los seguidores de

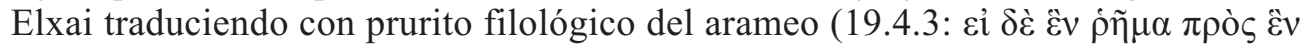

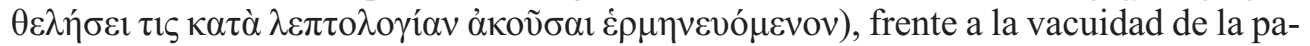

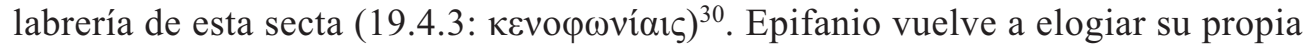
$\lambda \varepsilon \pi \tau o \lambda o \gamma i ́ \alpha$ cuando en pos de la objetividad de su obra cita extensamente los documentos herejes que han llegado a sus manos $(26.2 .1 ; 72.10 .4)$. En el ámbito de la oración y de la comunicación personal con Dios, la $\lambda \varepsilon \pi \tau o \lambda o \gamma i ́ \alpha$ es, según el obispo de Salamis, especialmente prescriptiva para los ortodoxos que se dirigen a Dios con una breve fórmula ${ }^{31}$. El hecho de que Epifanio cite que dos de sus modelos doctrina-

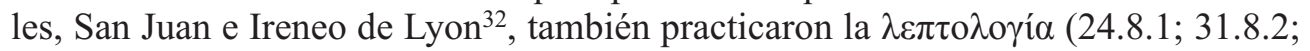
$51.12 .3 ; 51.15 .1-3)$ es un intento del obispo de validar su respeto por la literalidad trayendo a colación la autoridad de dos pilares de la ortodoxia cristiana.

Así pues, como ocurría con el empleo de $\lambda \varepsilon \xi 1 \theta \eta \rho \varepsilon ́ \omega$, el uso de $\lambda \varepsilon \pi \tau o \lambda o \gamma i ́ \alpha$ tiene una doble lectura en el Panarion. Desde una perspectiva religiosa, la práctica de la argumentación escrupulosa contribuiría a delimitar más claramente los límites de las doctrinas que constituían el pensamiento herético a finales del siglo IV. La noción de herejía en el pensamiento y obra de Epifanio siguen siendo objeto de debate dada la naturaleza flexible del término herejía ${ }^{33}$. En el caso de su uso en Epifanio, esta percepción es aún si cabe más acusada ya que las más de ochenta herejías a las que ataca en su Panarion no tienen en común ningún rasgo doctrinal o teológico salvo el hecho de ser una fuente de division which generates further division (...) heresy is false religion and includes all that is outside the unity of the one, holy, catholic and orthodox Church ${ }^{34}$. En este ámbito, la práctica de $\lambda \varepsilon \pi \tau o \lambda$ oүía

\footnotetext{
${ }^{28}$ Sería interesante estudiar el Panarion en el contexto de la formación de la literatura sobre bestiarios, que tanto predicamento tuvo en la Edad Media. Vid. J.J. García Arranz, «Texto Clásico e Imagen Medieval: una aproximación a la incidencia de la literatura antigua en el bestiario ilustrado», Norba-Arte 17 (1997), pp. 27-40.

${ }^{29}$ Sobre el sentido peyorativo que el término leptología podía llegar a tener en la Atenas clásica, vid. C. Na-

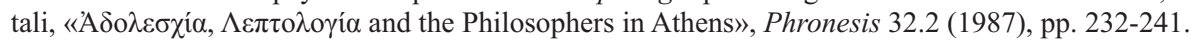

${ }^{30}$ Sobre la secta de Elxai, vid. J. Daniélou y H.I. Marrou, Nueva Historia de la Iglesia. Desde los orígenes hasta San Gregorio, trad. esp., Madrid, 1964, p. 99s.

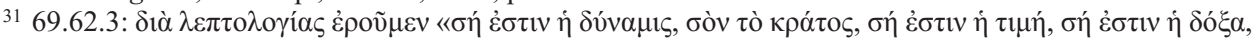

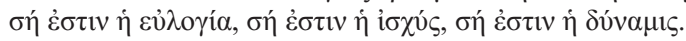

32 F.D. Williams, op. cit., p. XXIII. A. Pourkier, op. cit., pp. 59-63.

${ }^{33}$ Sobre el tema, vid. M. Marcos, «Qué es un hereje. Herejes en la historia», M. Marcos (ed.), Herejes en la Historia, Madrid, 2009, pp. 9-19.

${ }^{34}$ F.M. Young, «Did Epiphanius know what he meant by Heresy?», SP 17.1 (1982), p. 202. Vid. también E. Moutsoulas, «Der Begriff Häresie bei Epiphanius von Salamis», SP 7.1 (1966), pp. 362-371; A. Pourkier, op. cit., pp. 85-91. C. Riggi, 1967, op. cit., pp. 3-27 ofrece una opinión más moderada, especialmente para con los judíos.
} 
serviría como un marcador positivo y válido de la ortodoxia religiosa, en oposición a la búsqueda de lecturas heterodoxas característica de los herejes $\lambda \varepsilon \xi i ́ \theta \eta \rho \varepsilon \varsigma$. Así pues, el rigor religioso que propugnaba Epifanio encontró su plasmación literariay lingüística en el modo de ejercer la erudición filológica.

Desde un punto de vista cultural, el uso de $\lambda \varepsilon \pi \tau o \lambda o \gamma i ́ a$ revela que Epifanio fue un autor que supo crear su propio vocabulario y adaptarlo a su estricto ideario religioso. En este sentido, Williams reconoce la dificultad de traducir con un significado

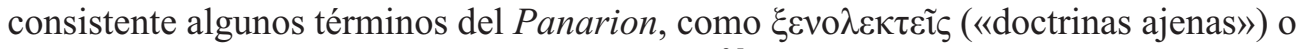
$\mu$ o $\chi \emptyset \eta \rho i ́ \alpha$ ( («argumentaciones pobres, falaces») $)^{35}$. Sin embargo, las distintas alusiones a $\lambda \varepsilon \pi \tau o \lambda$ o $\gamma$ ía tienen mayor sentido en el Panarion. Su presencia en tratados de retórica como los de Hermógenes, Frínico, Herodiano, o Alejandro el Rétor testimonia

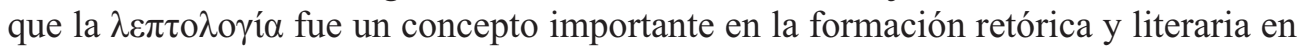

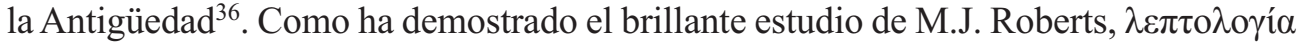
fue un concepto muy extendido en la poética, la retórica y las artes plásticas de la Antigüedad tardía. En su opinión, the minute attention to word selection, sound, and order is a necessary consequence of leptologia ${ }^{37}$. Por lo tanto, el empleo de $\lambda \varepsilon \pi \tau o \lambda o \gamma i ́ \alpha$ en el Panarion denota que la formación cultural de Epifanio fue lo suficientemente sólida como para servirse de un término de aparición frecuente en el ámbito de la crítica literaria y artística, e insertarlo en una heresiología.

A modo de conclusión, cabe destacar que Epifanio de Salamis se valió de un vocabulario de raigambre cristiana (nótese que, salvo Aulo Gelio, el resto de autores que se valen de $\lambda \varepsilon \xi 1 \theta \eta \rho \varepsilon ́(\omega$ son cristianos) en conjunción con una terminología propia de la tardo-antigüedad, atestiguada en manuales de retórica, con objeto de marcar más claramente los límites de la ortodoxia religiosa en el campo de la exégesis de las Escrituras. Además del comportamiento y de las creencias de cada secta, Epifanio consideró que la heterodoxia religiosa también se demostraba en el excesivo celo filológico que movía a buscar lecturas de las Escrituras alejadas del nicenismo ortodoxo.

\footnotetext{
${ }^{35}$ F.D. Williams, op. cit., p.XXIV.

${ }^{36}$ Hermg., Sobre las ideas 1.12; Alej. Rh., De Figuris 18; Frínico, Praeparatio Sofist. 83-85; Herod, Philetaeurus 38.

${ }^{37}$ M.J. Roberts, The Jeweled Style: poetry and poetics in Late Antiquity, Ithaca, 1989, p. 44.
} 